\title{
AN ALTERNATIVE 3D ADDRESS VISUALIZATION METHOD FOR BUILDINGS AND BUILDING INDEPENDENT SECTIONS WITH GIS-BASED 3D MODELLING APPROACH
}

\author{
S. Bediroglu ${ }^{1}$, V. Yıldırım² \\ ${ }^{1}$ Gaziantep University, City and Regional Planning Department \\ ${ }^{2}$ Karadeniz Technical University, Geomatics Department
}

KEY WORDS: 3D GIS, Address Information Systems, Geocoding, Numbering, Procedural Modelling, Rule Based Modelling

\begin{abstract}
:
Most commonly used detail type in 3D city modelling is building layer. One of the most important distinguishing point of buildings is independent sections. When the independent sections are examined in the context of Urban Information System (UIS), they have a multi-layered structure with their own characteristics. In address management processes, definition of the area belonging to a person, family or organization is realized through independent sections of buildings. In this study, it is aimed to model one the most important components of city objects such as building independent sections and road networks with GIS-based 3D modelling techniques. According to the results obtained from literature studies, answers were researched to the questions of what should be workflow of producing 3D models in the system and what should be in ideal 3D GIS database. Buildings and building independent sections were geocoded to provide some additional innovations to address mapping methods. Procedural modelling method was preferred as a GIS-based 3D modelling technique. Created models enable both the visualization of address data and their transfer to the $3 \mathrm{D}$ environment, as well as navigation. It provides some practical information. The designed system has been tested practically in Trabzon city.
\end{abstract}

\section{INTRODUCTION}

In the process of developing information technologies, public administration tends to turn from a single system management unit to a multiple management style in terms of Address Information System (AIS). The classical data processing and storage method leaves its place to more complex digital systems. One of these systems is the address information systems, which are based on numbering systems, where location-based address information is kept in databases, and which can be updated continuously. These systems eliminate the confusion caused by address data kept in different media and formats in all public and private institutions and the problems that may arise due to this. In this context, address information systems. These are the systems in which the address data in standard format are associated with the basic layers of the city such as roads and buildings, the necessary attribute information and databases of these layers are created. The necessary queries and analyzes can be made, the entire address inventory of the city is kept, and they are the basis for the information system applications to be made later.

Address data, which is among the various variations of spatial data, is one of the important components of geographical data and provides the function of displaying a geographical detail on the map as the most basic definition of the land particle (Kellison, 2012; Yıldırım and Ural, 2017). It ensures that address specific locations are accessible according to predetermined guidelines. Address data events are also critical when analyzing accidents (Davis and Fonseca, 2007; Küçük, Matçı and Avdan, 2018). In addition to reaching a certain location, the address plays an important role in associating information in various public institutions with each other and in creating strategic plans for the future. It is very difficult to base the complexly constructed road network and building structures on a regular address system in residential areas (Kılıç, 2017).
The use of geoinformation for enabling and facilitating smart city environments covers a wide range of fields including $3 \mathrm{D}$ modelling (Işıkdağ, 2020). Systems that can perform the functions expected from a GIS for real objects in the 3D world are called 3D GIS (Karaş and Yeşil, 2011).

The aim of the study is to contribute to the faster and more functional 3D modeling of buildings and their independent sections, which are among the important components of $3 \mathrm{D}$ digital city models. The system to be produced will support the solution of some GIS problems that cannot be solved in two dimensions in our country and in the world. One of these problems is incorrect address allocation problems and the system will provide accuracy control in address data thanks to its 3D features. In particular, it will contribute to the development of projects such as Mekansal Adres Kayit Sistemi (MAKS) and Ulusal Adres Veri Tabanı (UAVT), which are being carried out in our country, by supporting them with 3D. In the MAKS project, which is of critical importance in the current situation, a significant contribution will be made to address identification and geocoding problems, with the help of integration of the 3D geometric models of the independent sections, which are only defined as abstract structures and represented as verbal information, and the relevant address information with GIS. 


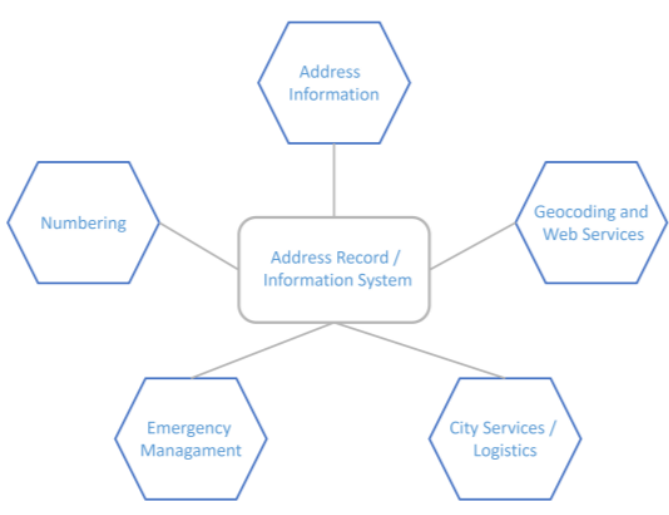

Figure 1. Address information system components

\section{METHODOLOGY}

\subsection{Geocoding (Address Matching)}

Geocoding is the process of converting verbal expressions into numerical values by converting addresses, place names and other geographical references to coordinates. Geocoding can be done effectively by GIS and increases functionality of UIS's. In contrast, the action converting coordinates into verbal address format is called reverse geocoding. Geocoding is the creation of XY coordinate segments from the referenced data model with specific elements of the description of a location. In general, it consists of basic steps such as decoding (fragmenting) the input address data, standardizing, indexing, and matching according to the best-fitting data (Zandbergen, 2008).

The historical process is examined geocoding renovation. US Cencus Bureau developed by Topologically Integrated Geographic Encoding and Referencing (TIGER) across the country with data model geocoding renovation work to reference data set was created (Klosterman and Lewin 1992; Dao, 2015). The TIGER dataset model offers a precise approach to the geographic resolution of address distribution problems (Drummond, 1995; Lee, 2009). Then, address point matching method was developed by Ordinance Survey in England in order to solve the address problem and convert textual expressions into geographic coordinates in internet-based GIS applications (Lee, 2009). Today, there are geocoding alternatives with many different features. Geocoded coordinates are used as reliable reference data to verify spatial accuracy in some studies . Compared to other data, geocoded data stands out with its low cost and precision accuracy (Stark, 2011; Ostermann and Spinsanti, 2011). Address geocoding is among the powerful tools for locating events and analyzing them on digital maps. Address matching provides economic contributions in local governments and enables administrative operations to be carried out sensitively and reliably (Zandbergen et al., 2012; Yildırım et al., 2014).

Geocode clearance is entered for any purpose of a location on the earth positional information geo-referenced is mapped to coordinates (Grubesic and Murray, 2004). Geocoding operations can be done with desktop software (eg Esri Adress Geocoder) or web applications (Geogle Geocoding API, Yahoo Geocoding API) (Cui, 2013).

\section{- $\quad$ Area Based Geocoding}

The process of performing address matching processes by creating a matrix by dividing the defined administrative divisions (neighborhood, zip region) in cities or districts into sub-areas is called area -based geocoding method. Positional precision is low. Areas subject to address mapping are divided into hierarchical grids and addresses are defined according to positions in the grid hierarchy. It is generally used in East countries such as Japan and Korea.

\section{- $\quad$ Street -based geocoding}

They are systems in which definitions are made according to how address matching processes are located along streets and avenues. It is frequently used in countries such as the USA and CANADA. In this method, spatial sensitivity is at a medium level and is frequently used by local governments.

\section{- $\quad$ Point matching}

They are systems created by establishing one-to-many or oneto-many relations with the direct coordinate values of the address components. This geocoding is the method supports high level accuracy. It is used in many countries around the world (England, Germany). In the point matching method, the coordinates of the apartment entrances for the buildings are converted into alpha-numeric values or verbal definitions and cross-correlated. In addition, addresses with touristic importance such as cafes, restaurants, parks, monuments, fountains, which are defined as important points, can be defined by the point matching method. With the help of point matching, it enables to establish a relationship with the verbal data represented by the location of the point that is directly subject to the address data.

\subsection{Numbering}

Numbering is the process of naming roads and numbering buildings according to the "Law on Numbering of Buildings and Naming Streets" dated 10.04.1927 and numbered 1003 and "Numbering Regulation" published in the Official Gazette (Resmi Gazete) dated 21/03/1963 and numbered 11361 . The purpose of numbering studies in the application book of the relevant law; as in all censuses and researches carried out to determine the social and economic structure of our country, it is of great importance to establish addresses and address system and to monitor the address qualities up-to-date in the works of all public institutions and organizations and the services to be provided by local governments. The variable of the Address Based Population Registration System (ADNKS) is the UAVT. The main purpose of the numbering work is the numbering the buildings and processing addresses of the numbered buildings into the UAVT

\subsection{Procedural 3D Modelling}

The first works that stand out in the definition and use of the procedural modeling method, which is based on the principle of defining the geometry of objects with procedures over parameters, are the activities carried out by (Parish and Müller, 2001). Towards 2008, Procedural Inc. created the City Engine software that works with procedural modeling. Later, this organization was purchased by ESRI with all rights. City Engine CGA shape grammer is a unique programming language for producing architectural 3D content. The term CGA is short definition of Computer Generated Architecture. The purpose of grammar-oriented modeling is to define rules that will refine a design by creating too much detail. These rules work on shapes that contain an OBB (in scope) geometry in the bounding box. 


\section{DEVELOPED METHODS: DESIGNING 3DADDRESS REGISTRATION SYSTEM (3D MAKS)}

How to record address data is explained in detail in the MAKS project implementation guide and numbering regulation. However, all current systems are designed in 2D and optimizations are required for integration with 3D systems. For this purpose, the design that will enable the integration of the existing MAKS project to 3D systems has been made and is explained below. The choice of geocoding method is critical for the efficient use of address registration systems. The advantages / disadvantages of innovative studies on address systems referred to in the literature section have been meticulously examined, and it has been concluded that the most compatible approach to the models and system to be produced within the scope of the study is "Point Matching" and geocoding management. One of the main reasons for making this judgment is that the method has a sensitive address matching capability compared to the metric, line and area -based methods (Dao, 2015). A second reason is that when it comes to the integration of the method with 3D systems, it is more applicable than street/line-based methods and may be more practical than areabased systems, and at the same time, area-based addressmatching methods are generally preferred in Far East countries. The 3D (X, Y, Z) coordinates of the building entrances, which can be obtained practically from the architectural floor plans studied in the study and which can be converted to GIS format in digital environment, reveal the consistency of choosing this approach. When the structure of CAD, GIS, Geocoding software used in the current situation is examined, it is concluded that geocoding services such as Pitney Bows, Google, Mapbox Arcgis Single House Locator support the point -based geocoding method but are not capable of meeting the desired 3D MAX expectations. It has been concluded that the targeted system capabilities can be achieved in case of improvement in the matching approach of this system. New GIS-based approaches are needed to establish a 3D address system. In order to fill the deficiency in this area with a new, functional approach, the model described and formulated below has been developed. While developing this method, knowledge of Cartography, GIS and Geometry was actively used.

In this section, the main goal is to determine the relative relationships between the main entrances of the buildings and their independent sections, to automatically measure metrics such as the length-angle value and to include the unique codes to be given to each independent section, so that individual codes also contain poor navigation information. The data obtained after the digitization and detail extraction processes include the coordinates of the building and independent section entrances. However, it is not possible to obtain the desired relative distances in these coordinates. Because the orientation of each building and the angle of its facade with the north is different. When the literature studies are examined, the principles of indoor networking or interior modeling are used to solve this problem. Although these methods are rich in terms of factors such as functionality, navigation capabilities and service diversity, model production processes take a long time and it seems consistent to be used in areas where it is needed because it brings extra time and labor burdens. In order to solve this problem, an approach has been developed to automatically measure metric units by using some formulations in GIS and cartography by referring to the facade where the entrance door of the building is located, and is explained in detail below.

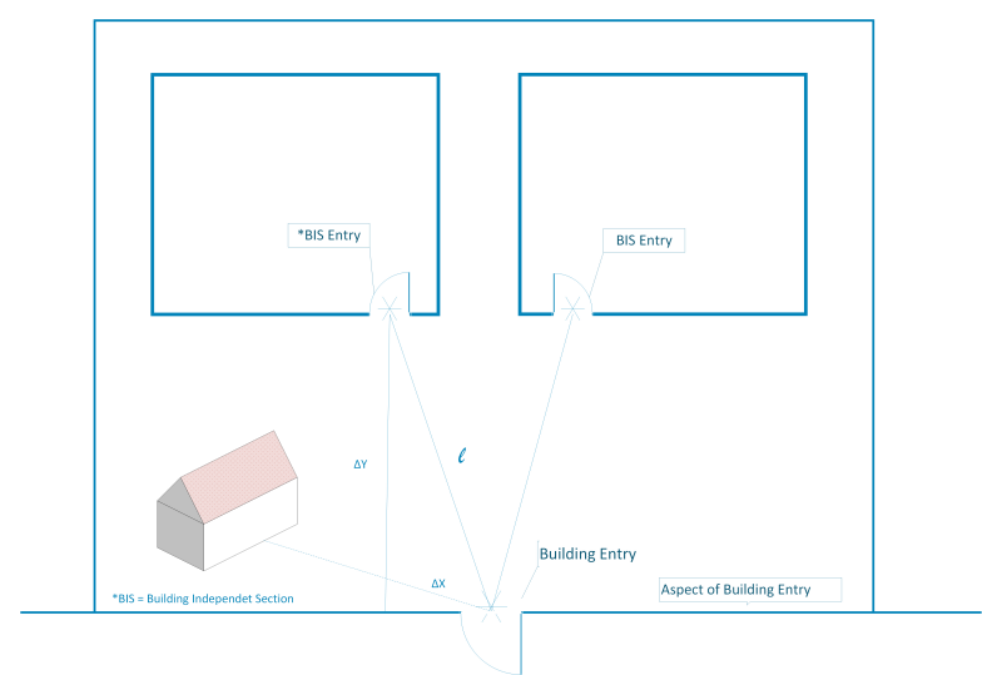

Figure 2. Representation of the geometric relationship between the building and the independent section entrances

Figure 2 shows the metric relations between the building entrance and the independent section entrances in a building. There are 4 unknowns;

- $\Delta \mathrm{X}$

- $\Delta \mathrm{Y}$

- 1

- $\mathrm{z}$

The variable 1, that is, the distance between two points, can be measured directly from the calculation of the coordinate differences with the help of the GIS program and printed on the attribute table. The $\mathrm{z}$ value can be calculated from the number of floors where the independent section is located. It is the $\Delta \mathrm{X}$ and $\Delta \mathrm{Y}$ values that are difficult to calculate and which, at first glance, are mistaken for believing that they can be obtained from the difference of normal X, Y values. A sequential process is followed to calculate the relative distances according to the facade where the door entrance of the building is located, and these processes are as follows:

- Recording the facade with the building entrance door as a line vector layer

- Individual sections of this line input layer "closest to the projection of detail" that is found to depend on the facade of the building projection determining the point where

- Calculation of the distance of the detected point to the building entrance door $(\Delta \mathrm{X})$ with the help of coordinates

- The last value to be calculated, $\Delta \mathrm{Y}$, is to be calculated using the Pythagorean theorem or the independent section facade projection point-Independent section entry point and coordinates.

These processes, which were explained, were carried out fully automatically with GIS software and calculation tools written in Python programming language after the required data sets were prepared .

In order for the calculated values to be converted into individual Independent Section IDs, the approach described below has been developed. Then the calculated values and the generated 
ID ' s 3D model of the geographic database has been associated added.

It has been ensured that individual codes containing navigation information are given to the independent sections and geocoding is done with the help of these codes . First of all, building entrances will be geocoded by point matching method and this method is an application that can be done easily with GIS software or GIS based web services. Integration with the 3D MAKS system will be achieved by using the metric values obtained in the previous stages in order to give individual codes to the independent sections and then perform geocoding applications .

\section{$[$ Left/Right][ $\Delta \mathrm{X}],[$ Forward/Backward] $[\Delta \mathrm{Y}],[\mathrm{Up} /$ Down $][\Delta \mathrm{z}]$}

It is based on the principle of expressing a 9-digit (6 digits-3 text) alphanumeric character string consisting of the above combination as a single piece in a single attribute column. Direction values for this operation will be represented by Right"L", Left-"S", Forward-“I”, Back-"G", Up-"Y", Down-“A". As a simple example, as a result of the calculations, an independent section entrance that is 10 meters to the left, 5 meters forward and 12 meters above the building entrance door will be represented by the code below.

\section{Ex: [S10I05Y12]}

As can be seen, the single code, which is the result of comprehensive geometric and mathematical calculations, is quite simple and also contains navigation information. Single codes can be used easily by the information system and also enable the integration of 3D addresses into independent sections . If the singular code, which is likely to recur in different buildings, is truly singular, it will become completely singular if the building entrances are expressed together with the geographical latitude longitude values or the binary coordinate values in the Cartesian coordinate system, and it will not be possible to repeat.

Ex: 38. 315643, 32.473897, S10I05Y12 code set has been developed as a method that does not repeat between independent departments throughout the country or the world, and leads first to the building and then to the relevant independent section. For the independent sections in very highrise or very large areas, where any distance value between the entrance and the entrance of the independent section should be more than 99 meters, the distance values are expressed as 3 digits. Since it is very difficult to find such structures (Skyscrapers), they will be marked as exceptional structures in the system and 3D MAKS, geocoding operations can be performed. In the proposed 3D MAX system, geocoding processes are explained with a pilot application. Relevant GIS data was provded from Trabzon Municipality. Most part of data was in raw CAD format and all they have been converted to GIS environment.

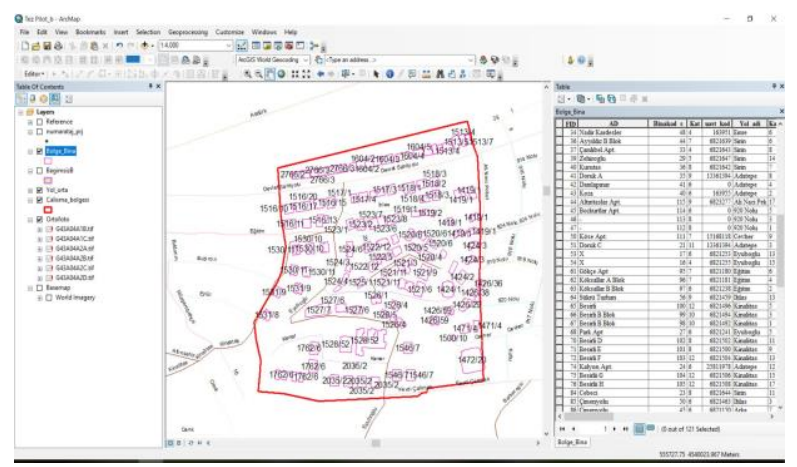

Figure 3. Creating a database in a GIS environment

It has been observed that one of the most fundamental problems in the realization of address information systems and related services is the standard defects in the way address data is recorded. Even in the same province, the same addresses are represented differently in different service units (electricity, water, natural gas). Even in invoices or notifications to subscribers, there are differences and errors. A standard address record order has been developed for Turkey in order to eliminate these standard disorders and to apply them to information systems supported address matching systematics. In order for the GIS-based 3D models to be produced to be used for address management purposes, a database design that contains existing address information as well as $3 \mathrm{D}$ guiding data containing weak navigation information has been made. Figure 4 shows $3 \mathrm{D}$ models of buildings with address data and texture. Figure 5 shows separately colored independent section 3D models of buildings with address data

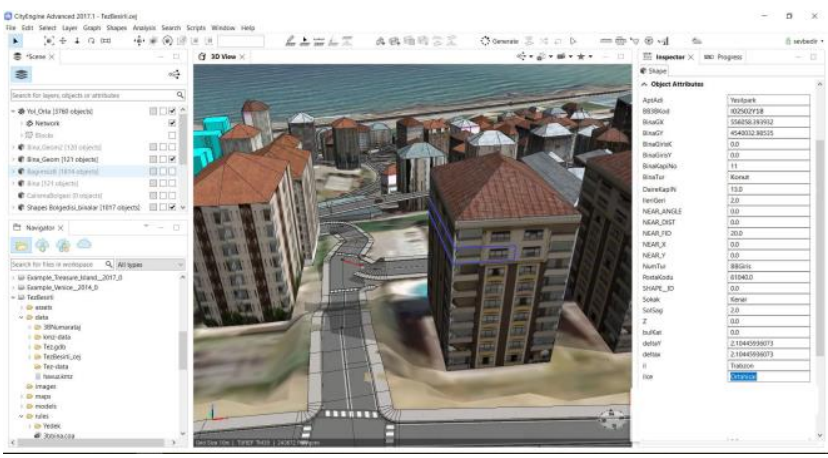

Figure 4. 3D models of buildings with address data and texture

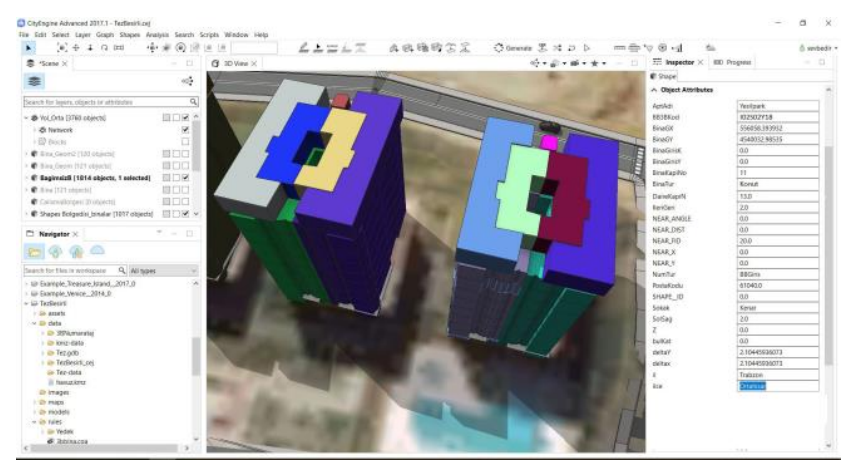

Figure 5. Separately colored independent section 3D models of buildings with address data 
Figure 6 shows a unique isolated wireframe view of a building independent section. At right side users may access to relevant address information.

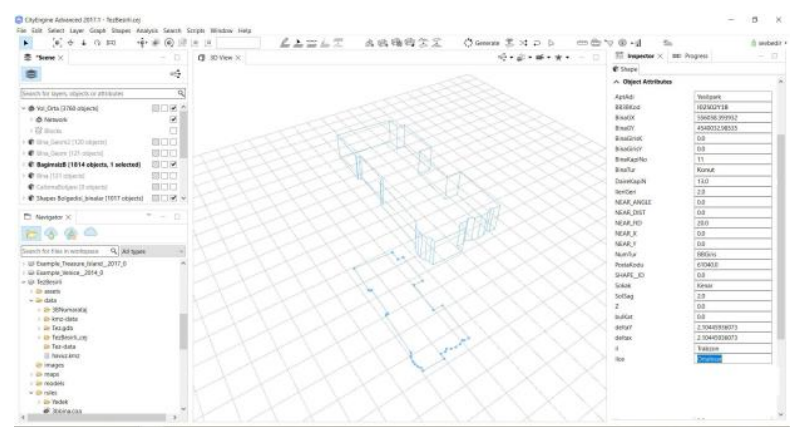

Figure 6. Isolated wireframe view of a building independent section

\section{CONCLUSONS}

The need for 3D systems in solving address problems is increasing. At the forefront of these problems is the inability to represent independent sections in 2D systems. Address data can be visualized through $3 \mathrm{D}$ systems, the database individual (unique) can be stored and used. Address data often corresponds to a specific area, not just a point. The representation of this area and the volumetric region is only possible in 3D systems. Since the 3D geocodes developed and containing poor navigation information are easy to produce, they have a functional role in the representation and differentiation of the 3D building and related independent sections that will be the subject of 3D modeling with this method. Another issue observed in the pilot study is the standard problem, which does not exist in address identification and numbering processes in Turkey. Serious problems arise in the aggregation of non-standardized address data and the application of address matching methods. In order to solve these address standard problems, a standard type of address must be registered in our country. A second issue is the inconsistencies in the independent section door numbers. In buildings such as public buildings, hotels and hospitals, separate numbers are given according to the floors. However, residences are generally numbered as $1,2,3,4 \ldots$ It is not possible to access floor information directly from consecutive numbers. However, in a door numbering system such as $101,102,201,202 \ldots$, the door number gives information about the floor information directly. With this approach, in the production of GIS-based 3D models of the numbered independent sections, the need to enter the floor information where the independent is located will be eliminated and the workload will be reduced to some extent. It is envisaged that an address registration standard that progresses hierarchically (from narrow region to wide region) can be quite functional in order to solve incorrect address problems, facilitate geocoding operations and reduce errors in 3D address representation.

\section{REFERENCES}

Cui, Y., 2013. A systematic approach to evaluate and validate the spatial accuracy of farmers market locations using multigeocoding services, Applied Geography, 41, 87-95.

Dao, J. T., 2015. A Comparison of Address Point and Street Geocoding Techniques in a Computer Aided Dispatch Environment, University of Southern California

Davis, C. A., Fonseca, F. T., 2007. Assessing the Certainty of Locations Produced by an Address Geocoding System, GeoInformatica, 11,1, 103-129.

Grubesic, T. H., Murray, A. T., 2004. Proceedings of the 24th urban data management symposium 2004, Assessing positional uncertainty in geocoded data.

Işıkdağ, Ü., 2020. AN IOT ARCHITECTURE FOR FACILITATING INTEGRATION OF GEOINFORMATION . International Journal of Engineering and Geosciences , 5 (1), 15-25 . DOI: $10.26833 /$ ijeg.587023

Karaş, İ. R., 2007. Objelerin Topolojik İlişsilerinin 3B CBS ve A $\breve{g}$ Analizi Kapsamında Değerlendirilmesi, Yıldız Teknik Üniversitesi, Fen Bilimleri Enstitüsü, İstanbul.

Kellison, M. T., 2012. Address points and a master address file: improving efficiency in the City of Chino, University of Southern California.

Kılıç. B., 2017. Adrese Dayalı Coğrafi Kodlama İşleminde Kalite Araştırması. Yüksek lisans Tezi Harita Mühendisliği Anabilim Dalı Uzaktan Algılama ve Cbs Programı. T.C. Yıldız teknik Üniversitesi Fen Bilimleri Enstitüsü

Klosterman, R. E., Lew, A. A., 1992. Tiger Products for Planning, Journal of the American Planning Association, 58,3, 379-385.

Küçük Matci, D., Avdan, U., 2018. Address standardization using the natural language process for improving geocoding results, Computers, Environment and Urban Systems, 70, 1-8.

Lee, J., 2009. GIS-Based Geocoding Methods for Area-Based Addresses and 3D Addresses in Urban Areas, Environment and Planning B: Planning and Design, 36,1, 86-106.

MAKS Tanımlayıcı Dökümanı, 2012. T. C. İçişleri Bakanlığı. Mekansal Adres Kayıt ve Çevrimiçi Emlak ve İnşaat İzinleri Projesi

Müeller, P., Wonka, P., Haegler, S., Ulmer, A., Gool, L. V. 2006. Procedural modeling of buildings, ACM SIGGRAPH 2006 Papers, Boston, Massachusetts 614-623. M., M., EGIS 1990 1990, Amsterdam, The Netherlands, A formal data structure for 3D vector maps, 2: 770-781.

Ostermann, F.O., Spinsanti, L. 2011. A conceptual workflow for automatically assessing the quality of volunteered geographic information for crisis management. The 14th AGILE International Conference on Geographic Information Science: Advancing Geoinformation Science for a Changing World. editor / S. Geertman ; W. Reinhardt ; F. Toppen. Association of Geographic Information Laboratories for Europe (AGILE), 2011. 
Stark, H. J. 2011. Quality assessment of volunteered geographic information using openweb map services within open addresses. In A. Car, G. Griesebner, \& J. Strobl (Eds.), Geospatial crossroads (pp. 101e110). Berlin: Herbert Wichmann Verlag.

Y1ldırım, V., Ural, H. A. 2017. Geographic information system for prevention of property tax evasion, Proceedings of the Institution of Civil Engineers - Municipal Engineer, 0,0, 1-11.

Yıldırım, V., Yomralığlu, T., Nişancı, R., İnan, H. İ, 2014. The Turkish Street Addressing System (TUSAS) and Geocoding Challenges, Proceedings of the Institution of Civil Engineers - Municipal Engineer 167.

Zandbergen, P. A., 2008. A comparison of address point, parcel and street geocoding techniques, Computers, Environment and Urban Systems, 32,3, 214-232.

Zandbergen, P. A., Hart, T. C., Lenzer, K. E., Camponovo, M. E., 2012. Error propagation models to examine the effects of geocoding quality on spatial analysis of individual-level datasets, Spatial and Spatio-temporal Epidemiology, 3,1, 69-82. 